\title{
Breast and Ovarian Cancer in Young Women of the Arabian Gulf Region: Relationship to Age
}

\author{
Sarah Al-Gahtani' ${ }^{1}$, Suhair Abozaid ${ }^{2}$, Elham Al-Nami' ${ }^{1}$, Leen Merie' ${ }^{1}$, Ayana Al-Yousef ${ }^{1}$, \\ Mohamed M. Shoukri ${ }^{3,4^{*}}$ \\ ${ }^{1}$ College of Medicine, Al-Maarefa University of Science and Technology, Riyadh, KSA \\ ${ }^{2}$ Department of Immunity and Infection, Research Center King Faisal Specialist Hospital \& Research Center, \\ Riyadh, KSA \\ ${ }^{3}$ Department of Cell Biology, Research Center King Faisal Specialist Hospital \& Research Center, Riyadh, KSA \\ ${ }^{4}$ College of Medicine, Al-Faisal University, Riyadh, KSA \\ Email: "shoukri@kfshrc.edu.sa
}

Received 25 June 2016; accepted 19 August 2016; published 22 August 2016

Copyright (C) 2016 by authors and Scientific Research Publishing Inc.

This work is licensed under the Creative Commons Attribution International License (CC BY).

http://creativecommons.org/licenses/by/4.0/

(c) (7) Open Access

\begin{abstract}
It is widely known that cancer is a disease of "old-age". However available data show that this is not the case for many types of cancers. Incidences of breast and ovarian cancers have varying rates of change with age. Breast cancer data of Arabian-gulf women, show that the incidence rates increase with age and reach a maximum at 39 year. It then declines linearly with age to about 55 years. The rate of increase and its changes with age are similar to those of many other countries. In the premenopausal phase the relationship between incidence and age could be adequately modeled using a linear model for the logarithmic transformations of age and incidence. Similar observations are made for the ovarian cancer incidences. Results: It is shown that the rate of increase in breast and ovarian cancer incidence with respect to age is increasing in the premenopausal ages. Moreover, the burden of the disease with respect to mortality and "Disability Adjusted Life Years" or DALY, varied considerably among the six gulf countries. Conclusions: We conclude, based on the age incidence relationship that the number of cancer cases may double in the next period that follows our study period (1998-2009). Moreover, if the six countries have identical relationship between age and the two types of cancer, there should be an integrated and unified effort to have a common strategy for prevention and control.
\end{abstract}

\section{Keywords}

Gulf Cancer Registry, Breast and Ovarian Cancers, Risk Factors, DALY, Incidence Rates,

\footnotetext{
*Corresponding author.
} 


\section{Linear Models}

\section{Introduction}

Cancer is a disease in which cells in the body grow out of control. When cancer starts in the breast, it is called breast cancer. About 7 out of 100 women (or 7\%) will be diagnosed with breast cancer by the time they turn 70 years old. Ovarian cancer is far less common. About 1 out of 100 women (or 1\%) will be diagnosed with ovarian cancer by age 70 . Though it is less common than breast cancer, ovarian cancer causes more deaths than any other cancer of the female reproductive system [1].

While breast and ovarian cancers are most common in older women (about $89 \%$ of breast cancers occur in women older than 45 years of age), they can and do occur in younger women. However the rates of change in the incidence differ in both cancers.

The main objective of this paper is to evaluate the burden of breast and ovarian cancers in the Arabian Gulf States (AGS): namely Bahrain, Kingdom of Saudi Arabia (KSA), Kuwait, Oman, Qatar, and United Arab Emirates (UAE) in terms of mortality and disability. We also present the recent statistics of two important risk factors: obesity and diabetes. Since age is the most important risk factor for both types of cancer we develop linear models to investigate the relationship between cumulative incidence and age, and the changing rate of change. We use the cumulative incidence data from the Gulf Cancer Registry in the interval 1998-2009. We demonstrate that there is a considerable similarity among the AGS in the rate of change across age groups. The paper is structured as follows: In Section 2 we briefly discuss risk factors associated with breast and ovarian cancers. In Section 3 a comparison among the 6 AGS is made with respect to mortality and disability. The relationship between both types of cancers is examined in Section 4, and a general discussion is presented in Section 5.

\section{Risk Factors of Breast and Ovarian Cancers}

The main risk factors for both diseases are summarized as follows:

Age. A woman's risk of developing breast and ovarian cancer increases with age. Women of all ages have a risk of breast and ovarian cancer, but women over 50 are more likely to develop it. Sixty-eight percent (68\%) of women with ovarian cancer are older than 55 , and 32\% are younger than 55 [2].

Family History. Women with a first-degree relative (mother, daughter, or sister) with either breast or ovarian cancer have about a three times higher risk of developing the disease. This risk increases when two or more first-degree relatives have been diagnosed with ovarian cancer. Therefore understanding the family history is paramount to reduce the risk of both diseases

Genetics. About $10 \%$ to $15 \%$ of ovarian cancers occur because a genetic mutation (change) has been passed down within a family. A mutation in the BRCA1 or BRCA2 gene is associated with an increased risk of ovarian cancer and breast cancer [1] [2].

About 12 percent of women in the general population will develop breast cancer sometime during their lives [3]. By contrast, according to the most recent estimates, 55 to 65 percent of women who inherit a harmful BRCA1 mutation and around 45 percent of women who inherit a harmful BRCA2 mutation will develop breast cancer by age 70 years [4] Ovarian cancer: About 1.3 percent of women in the general population will develop ovarian cancer sometime during their lives [4]. By contrast, according to the most recent estimates, 39 percent of women who inherit a harmful BRCA1 mutation [5] [6] and 11 to 17 percent of women who inherit a harmful BRCA2 mutation will develop ovarian cancer by age 70 years [5] [6].

Components of Metabolic Syndrome: Obesity and Diabetes. Recent studies have shown that women who were obese in early adulthood are 50\% more likely to develop ovarian cancer. One study, using NCI Surveillance, Epidemiology, and End Results (SEER) data, estimated that in 2007 in the United States, about 34,000 new cases of cancer in men (4 percent) and 50,500 in women (7 percent) were due to obesity. The percentage of cases attributed to obesity varied widely for different cancer types but was as high as 40 percent for some cancers, particularly endometrial cancer and esophageal adenocarcinoma.

Table 1 \& Table 2 provide projections of the future health and economic burden of obesity in 2030 estimated that continuation of existing trends in obesity will lead to about 500,000 additional cases of cancer in the United 
Table 1. Prevalence of obesity in the AGS. Adapted from [9].

\begin{tabular}{ccccccc}
\hline Obesity level & Bahrain & Kuwait & Oman & KSA & Qatar & UAE \\
\hline Overweight & 75.2 & 84.3 & 73.4 & 74.2 & 78.5 & 60.6 \\
Obese & 42.9 & 58.6 & 36.9 & 44.4 & 54.7 & 44.2 \\
\hline
\end{tabular}

Table 2. Estimated and projected prevalence of diabetes in the AGS [10].

\begin{tabular}{ccccccc}
\hline Diabetes & Bahrain & Kuwait & Oman & KSA & Qatar & 17 \\
2010 & 15.4 & 14.6 & 13.4 & 16.8 & 17.9 \\
2030 & 17.3 & 16.9 & 14.9 & 18.9 & 21.4 \\
\hline
\end{tabular}

States by 2030 [7] [8].

\section{Burden of Breast and Ovarian Cancers in the AGS}

According to the National Institutes of Health, breast cancer was estimated to cost \$209.9 billion a year in 2005, of which $\$ 118.4$ billion was due to mortality cost (lost productivity by the death of patients), $\$ 74.0$ billion was due to direct medical costs (money spent for healthcare), and $\$ 17.5$ billion was due to morbidity cost (the cost of lost productivity due to illness [11].

On the other hand and due to poor prognosis and rigorous treatment protocols [11], ovarian cancer patients often suffer high distress at the time of diagnosis and during treatment [12] [13], potentially placing them at elevated risk for other co-morbidities. Another problem is that ovarian cancer surgery initiates menopause in pre-menopausal patients [12]. Depression is common among individuals with cancer and has been associated with decreased quality of life [14] [15]. In Table 3, adapted from [11] we show the changes between two selected years 2009, and 2013 in age standardized death rates in the six AGS for both breast and ovarian cancers.

As can be seen there are large variations in rates among the six countries. While there is decrease in age standardized mortality rates (ASMR) attributed to breast cancer in Bahrain, Qatar and UAE, the other three countries encountered increase. On the other hand, all the six states showed considerable decreases in the ASMR attributed to ovarian cancer in 2013 as compared to 2009. However the decreases in the ASMR were quite different among the six countries.

The other burden caused by breast and ovarian cancer of importance is the Disability-adjusted life year (DALY). The disability-adjusted life year or DALY is a summary measure of public health widely used to quantify burden of disease. In the DALY philosophy, every person is born with a certain number of life years potentially lived in optimal health. People may lose these healthy life years through living with illness and/or through dying before a reference life expectancy. These losses in healthy life years are exactly what is measured by the DALY metric [16] [17]. Ten DALYs, for instance, correspond to ten lost years of healthy life, attributable to morbidity, mortality, or both.

On a population level, diseases with a higher public health impact will thus account for more DALYs than those with a lesser impact. Table 4, adapted from [11] shows the variations in DALY figures for both cancers in the six countries. The main purpose of producing these figures, have been to assess and monitor regional health and to set priorities that should be shared among these six countries. As can be seen from Table 4, the rates in DALY decreased for both cancers in Bahrain, Qatar, KSA, and UAE, with varying rates of change.

\section{Relationship of Breast and Ovarian Cancer to Age}

\subsection{Data and Methods}

In general, population-based registries are organizations for the systematic collection, storage, analysis, interpretation and reporting of data on subjects with cancer. They seek to collect data on all new cases of cancer occurring in a well-defined population. Usually, the population is that which is resident in a particular geographical region. As a result, and in contrast to hospital-based registries, the main objective of this type of cancer registry is 
Table 3. Age standardized death rates in the six AGS. Breast cancer deaths are the first entry in the table, and the ovarian cancer deaths are in the second entry.

\begin{tabular}{|c|c|c|c|c|c|c|}
\hline \multirow{2}{*}{ Country } & \multicolumn{3}{|c|}{ Age standardized rate/100,000 } & \multicolumn{3}{|c|}{ Death in thousands } \\
\hline & 1990 & 2013 & \% change & 1990 & 2013 & $\%$ change \\
\hline \multirow{2}{*}{ Bahrain } & 10.75 & 8.58 & -20.19 & 0.03 & 0.07 & 133 \\
\hline & 2.95 & 2.53 & -14.24 & 0.01 & 0.01 & 0.00 \\
\hline \multirow{2}{*}{ Kuwait } & 5.85 & 6.02 & 2.91 & 0.05 & 0.10 & 100 \\
\hline & 1.91 & 1.29 & -32.5 & 0.01 & 0.02 & 100 \\
\hline \multirow{2}{*}{ Oman } & 3.71 & 4.11 & 10.78 & 0.03 & 0.07 & 133 \\
\hline & 1.33 & 1.27 & -4.50 & 0.01 & 0.02 & 100 \\
\hline \multirow{2}{*}{ Qatar } & 6.44 & 4.67 & -27.48 & 0.01 & 0.04 & 300 \\
\hline & 1.09 & 1.06 & -2.75 & 0.00 & 0.00 & 0.00 \\
\hline \multirow{2}{*}{ KSA } & 3.14 & 3.55 & 13.06 & 0.22 & 0.49 & 123 \\
\hline & 1 & .9 & -10 & 0.06 & 0.10 & 67 \\
\hline \multirow{2}{*}{ UAE } & 5.94 & 4.97 & -16.33 & 0.04 & 0.16 & 300 \\
\hline & 1.67 & 1.25 & -25.6 & 0.01 & 0.03 & 200 \\
\hline
\end{tabular}

Table 4. The first entries are the DALY figures for breast cancer, and the second entry are the DALY figures for ovarian cancer.

\begin{tabular}{ccccccc}
\hline \multirow{2}{*}{ Country } & \multicolumn{3}{c}{ Age standardized rate/100,000 } & \multicolumn{3}{c}{ DALY in thousands } \\
\cline { 2 - 7 } Bahrain & 1990 & 2013 & \% change & 1990 & 2013 & \% change \\
& 330.21 & 320.7 & -30 & 1 & 2.54 & 154 \\
& 70.5 & 51.8 & -26.6 & 0.17 & 0.42 & 147 \\
Kuwait & 158.79 & 163.6 & 3.04 & 2.13 & 3.76 & 77 \\
& 44 & 31 & -29.6 & 0.5 & 0.62 & 24 \\
Oman & 108 & 118 & 9 & 1.03 & 2.38 & 131 \\
& 32.8 & 28.4 & -13.3 & 0.26 & 0.46 & 76.9 \\
Qatar & 176 & 107 & -39 & 0.54 & 1.4 & 161 \\
& 22.42 & 19.25 & -14.1 & 0.04 & 0.14 & 250 \\
KSA & 94 & 75 & -19 & 8 & 14.6 & 82.2 \\
& 24.34 & 16.1 & -34 & 1.73 & 2.52 & 45.7 \\
\hline
\end{tabular}

to produce statistics on the occurrence of cancer in a defined population and to provide a framework for assessing and controlling the impact of cancer in the community. Thus, the emphasis is on epidemiology and public health. The uses of population-based cancer registration data may be summarized as follows:

1) They describe the extent and nature of the cancer burden in the community and assist in the establishment of public health priorities.

2) They may be used as a source of material for etiological studies.

3) They help in monitoring and assessing the effectiveness of cancer control activities.

\subsection{Cancer Registry of the Arabian Gulf States}

The gulf center for cancer registration was established in 1998 as a collaborative venture to collect and provide 
data for cancer incidence of the six gulf-states; Bahrain, Kingdom of Saudi Arabia (KSA), Kuwait, Oman, United Arab Emirates (UAE) and Qatar. In 2011 the gulf center for cancer registration was given the name "Gulf Center for Cancer Control and Prevention" (GCCCP) to monitor the cancer control and prevention strategies of the six gulf-states.

Between 1998 and 2009 the age adjusted cumulative incidence of cancer in the six countries was 119,000 [18]. The reported breast cancer cases were 14,700 cases or $12 \%$ of all cancers, and the reported ovarian cancer cases were 2265, or $1.9 \%$ of all cancers. Figure 1 shows the relationship between the log-count (natural logarithm of the number of cases) of breast cancer cases and the log-midpoint of age. As can be see, the rates and the rates of changes are clearly divided into two distinct phases separated at about age 49. The first phase represents the early years of reproductive life, and the second phase represents the post-menopausal years. This trend in phase (1) is in agreement with the suggestion of Lilienfeld and Johnson [19] that the incidence increases by the same rate with each increment of age. The constancy of the rate of change in phase 1) is of quantitative importance because if the rate of change remains the same in the age groups 35,40 , and 50 , the lifetime and incidence of breast cancer in AGS would be more than doubled in the next 12 years to follow. In phase 2), the decline in incidence as women ages increase is shown.

We therefore decided to model the relationship between incidence and age separately for each phase of age (phase (1) = age less than 49, and Phase (2) = when age is above 49). Figure $2 \&$ Figure 3 depict this relationship. The relationship between age and ovarian cancer incidence are shown in Figure 4 and Figure 5.

The relationship between age and the number of breast cancer (BC) cases for phase (1) is adequately modeled by a simple linear regression model. An indicative of the goodness of fit of this relationship is the value of the

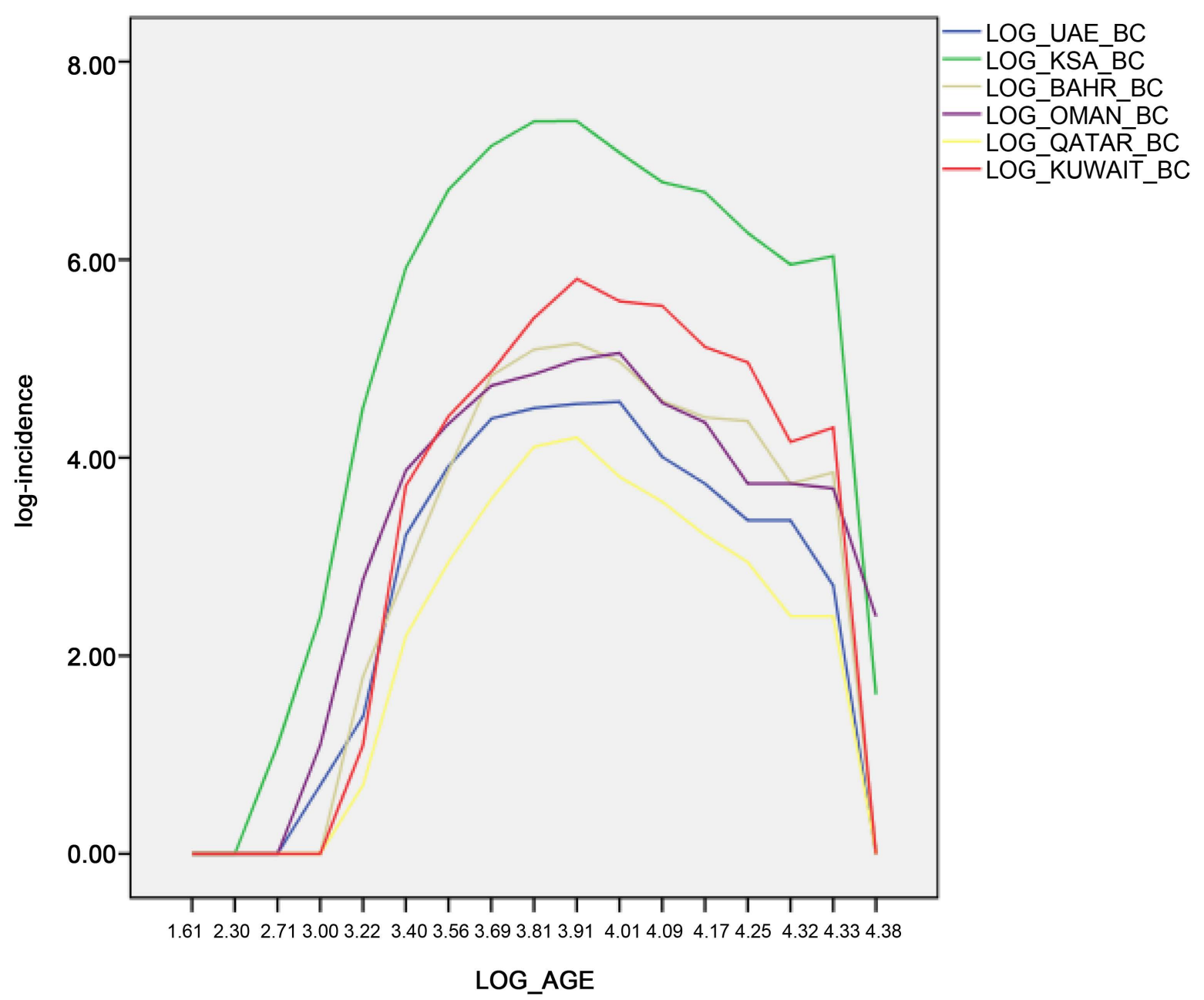

Figure 1. Cumulative breast cancer cases over the period 1998-2009 for all ages. 


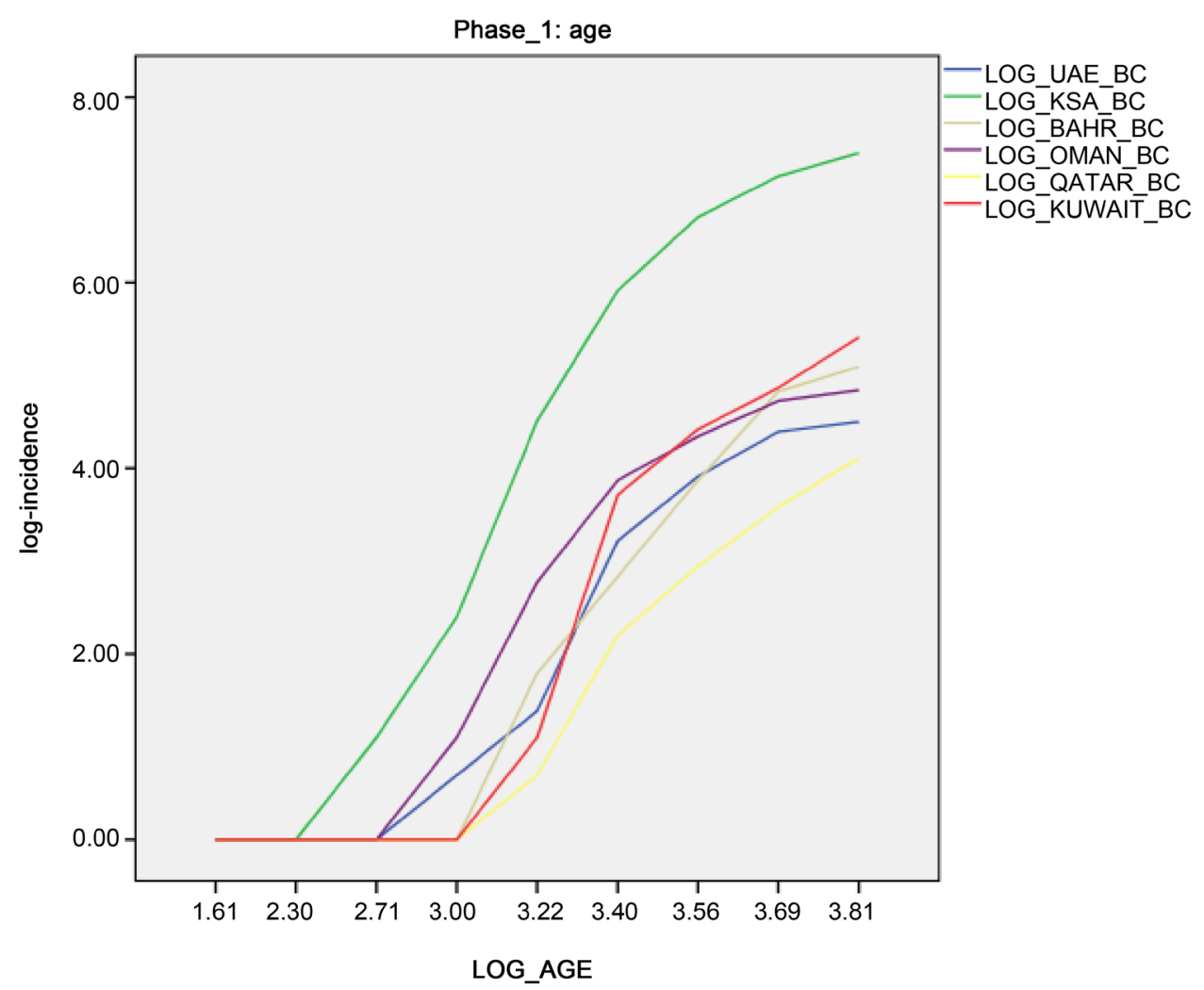

Figure 2. Cumulative count of breast cancer for the period 1998-2009 for phase (1).

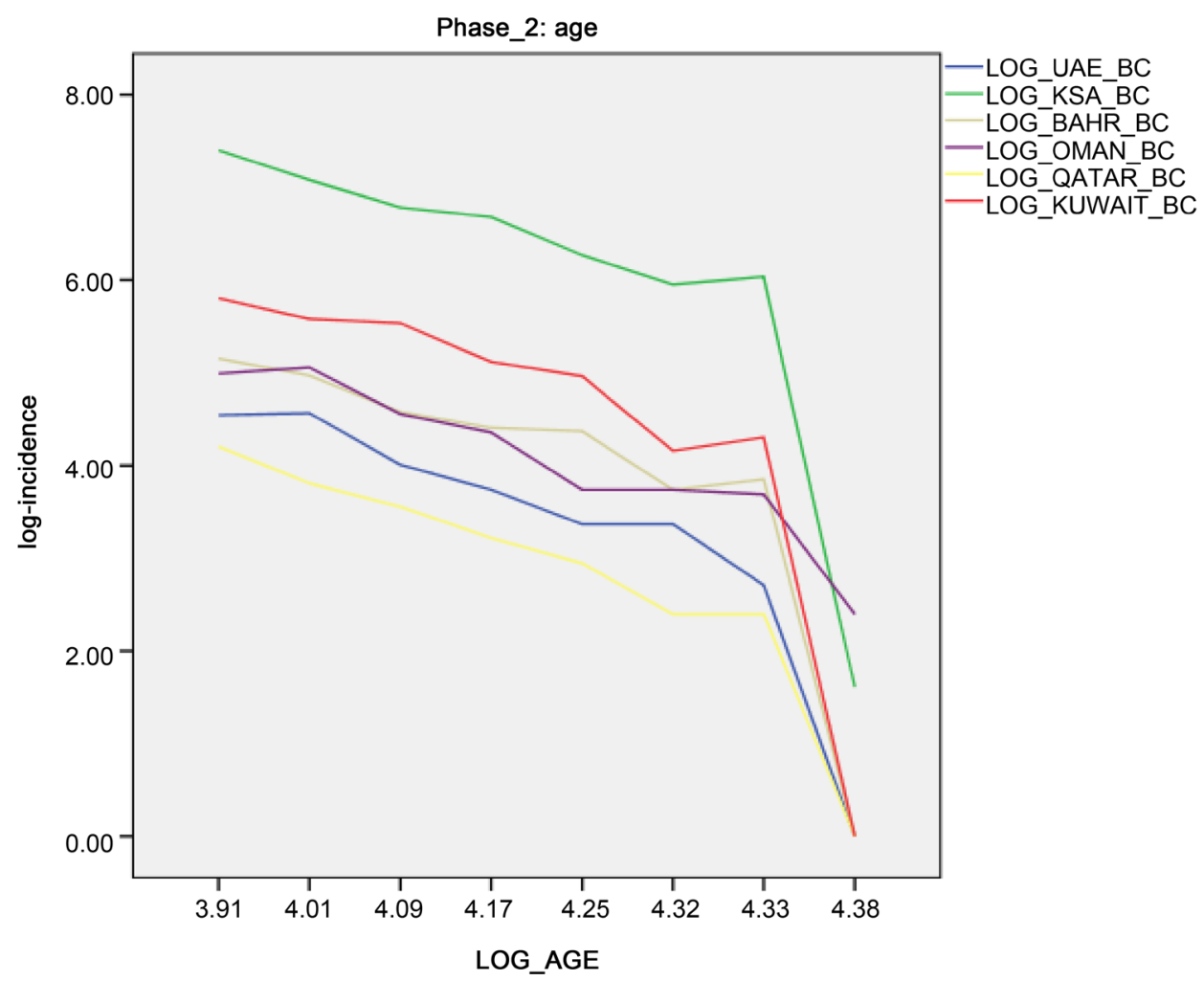

Figure 3. Incidence of breast cancer for the age phase (2). 


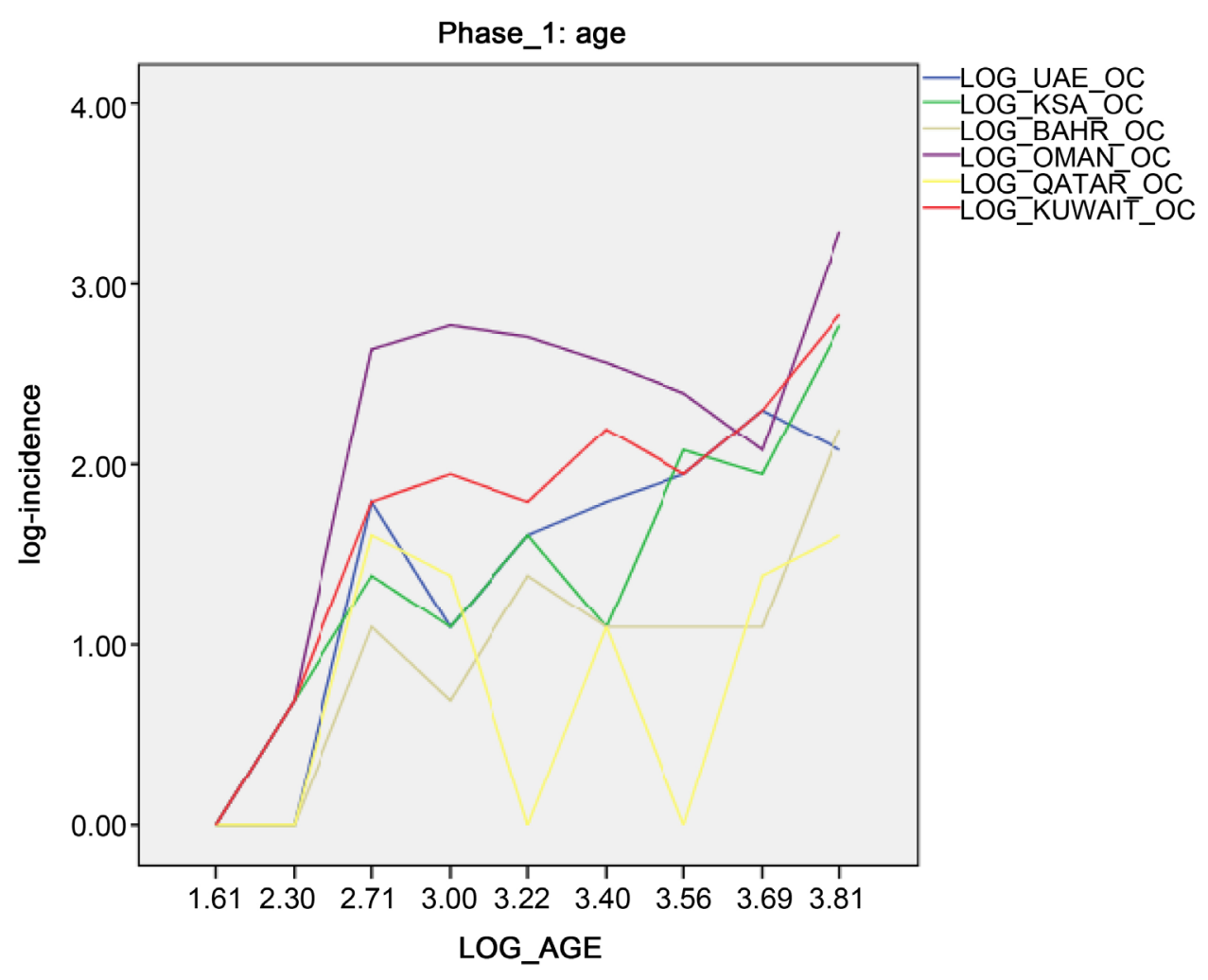

Figure 4. Incidence of ovarian cancer for the age periods above below 50 years of age.

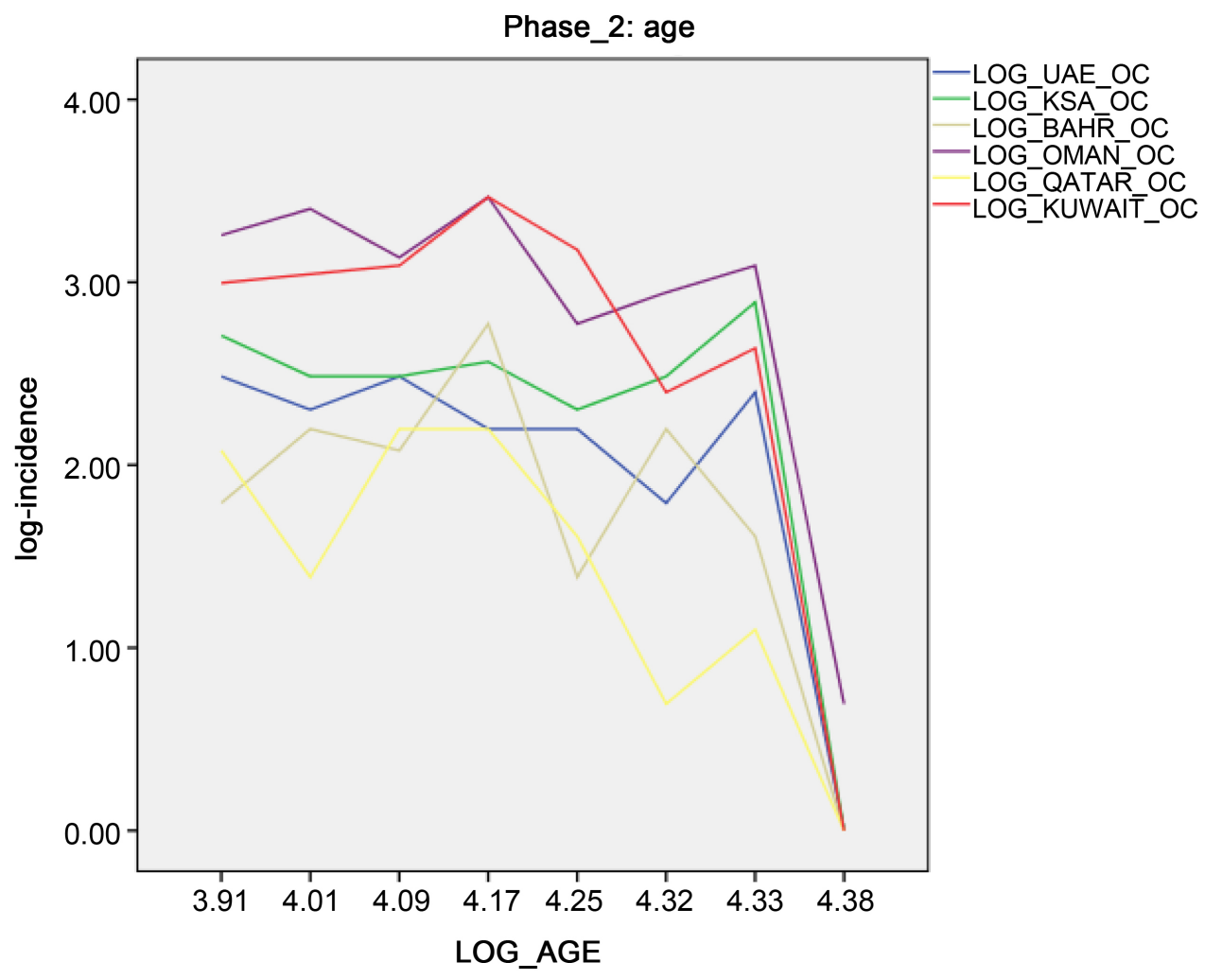

Figure 5. Incidence of ovarian cancer for the age periods above 50 years. 
coefficient of determination $R^{2}$. Values of the coefficient of determination above $70 \%$ indicate a good fit, and this is the case except for Qatar and Kuwait. Since our focus is on young women we shall give special attention to the relationship between age and the count in phase (1). Using SPSS version 20, we fitted the relationship [20]:

$$
\begin{aligned}
& Y=\log (\text { count })=\alpha+\beta \log (\text { age mid point }) \equiv \alpha+\beta x . \\
& \text { or count }=\alpha^{\prime}(\text { age })^{\beta}, \text { where } \alpha^{\prime}=\mathrm{e}^{\alpha}
\end{aligned}
$$

The results are presented in Table 5. Now we need to verify the hypothesis of homogeneity of the rates of change in the number of breast cancer cases with respect age. This hypothesis can be tested using the Cochran's Chi-square test defined as follows:

First, we define $\bar{\beta}=\sum_{i=1}^{6} w_{i} \hat{\beta}_{i} \mid \sum_{i=1}^{6} w_{i}$, where $w_{i}=\left(\operatorname{var}\left(\hat{\beta}_{i}\right)\right)^{-1}$. The chi-square test is:

$$
Q=\sum_{i=1}^{6} w_{i}\left(\hat{\beta}_{i}-\bar{\beta}\right)^{2}
$$

And the hypothesis of homogeneity of rates of change is established when p-value of the above Q-statistics is above $5 \%$. For BC cases the results are summarized in Table 7 . We may conclude that all the AGS have the same rate of change in BC cases since all the p-values are above the cut-off value $5 \%$ of the type I error rate. The common estimate of the rates of change in BC count with respect to age are $\bar{\beta}=2.68 \pm 0.228$, and $\bar{\beta}=-5.66 \pm 0.688$ for phases (1) and (2) respectively.

The pattern of relationship between the OC incidence and age is similar to the relationship between BC and age as can be seen in Table 6. There is increase in the incidence rate with age in phase (1) and a decrease in the rates in phase (2). The results are shown in Table 4. Except for the country of Qatar, there is an excellent fit for the linear model in phase (1), and a very poor fit in phase (2). Similarly, the homogeneity test is accepted and the p-values are reported in Table 7. The common rates of change in the OC incidence with respect to age are $\bar{\beta}=1.02 \pm 0.08$, and $\bar{\beta}=-3.07 \pm 0.697$ for phases (1) and (2) respectively.

Homogeneity of rate of change in number of cancer cases among the 6 countries was established separately for each phase and for BC, and OC.

\section{Discussion}

\begin{tabular}{|c|c|c|c|c|}
\hline Country & Phase & $\begin{array}{c}Y=\log (\text { count })=\alpha+\beta x \\
x=\log (\text { midpoint of the age intervals })\end{array}$ & $\operatorname{SE}(\beta)$ & $R^{2}$ \\
\hline \multirow{2}{*}{ UAE } & 1 & $-5.2+2.4($ log age $)$ & 0.52 & $75 \%$ \\
\hline & 2 & $32.2-6.9(\log$ age $)$ & 2.2 & $62 \%$ \\
\hline \multirow{2}{*}{ BAH } & 1 & $-5.7+2.5(\log$ age $)$ & 0.62 & $71 \%$ \\
\hline & 2 & $33.04-7($ log age $)$ & 2.8 & $50 \%$ \\
\hline \multirow{2}{*}{ KSA } & 1 & $-8.2+4($ log age $)$ & 0.56 & $87 \%$ \\
\hline & 2 & $38-7.7$ (log age) & 3.2 & $50 \%$ \\
\hline \multirow{2}{*}{ Oman } & 1 & $-5.7+2.7(\log$ age $)$ & 0.5 & $81 \%$ \\
\hline & 2 & $23.8-4.7($ log age $)$ & 0.9 & $82 \%$ \\
\hline \multirow{2}{*}{ Qatar } & 1 & $-4.4+1.9(\log$ age $)$ & 0.52 & $66 \%$ \\
\hline & 2 & $30.3-6.6(\log$ age $)$ & 1.7 & $71 \%$ \\
\hline \multirow{2}{*}{ Kuwait } & 1 & $-6+2.7($ log age $)$ & 0.71 & $68 \%$ \\
\hline & 2 & $38-8.1(\log$ age $)$ & 3.2 & $51 \%$ \\
\hline
\end{tabular}

Cancer poses a major threat to public health worldwide, and incidence rates have increased in most countries

Table 5. Rates of change in BC count for the two phases of age. 
Table 6. Rates of change in OC count for two phases of age.

\begin{tabular}{|c|c|c|c|c|}
\hline Country & Phase & $Y=\log ($ count $)=\alpha+\beta \log ($ age $)$ & $\mathrm{SE}(\beta)$ & $R^{2}$ \\
\hline \multirow{2}{*}{ UAE } & 1 & $-1.9+1.1($ log age $)$ & 0.19 & $81 \%$ \\
\hline & 2 & $14.4-2.98($ log age $)$ & 1.6 & $36 \%$ \\
\hline \multirow{2}{*}{ BAH } & 1 & $-1.7+1(\log$ age $)$ & 0.19 & $81 \%$ \\
\hline & 2 & $13.1-2.59(\log$ age $)$ & 2 & $22 \%$ \\
\hline \multirow{2}{*}{ KSA } & 1 & $-1.4+0.8($ log age $)$ & 0.19 & $70 \%$ \\
\hline & 2 & $11.6-2.35($ log age $)$ & 1.8 & $23 \%$ \\
\hline \multirow{2}{*}{ Oman } & 1 & $-1.6+1.25($ log age $)$ & 0.31 & $70 \%$ \\
\hline & 2 & $16.2-3.2($ log age $)$ & 1.8 & $35 \%$ \\
\hline \multirow{2}{*}{ Qatar } & 1 & $-0.67+0.48($ log age $)$ & 0.36 & $21 \%$ \\
\hline & 2 & $15.6-3.4($ log age $)$ & 1.3 & $52 \%$ \\
\hline \multirow{2}{*}{ Kuwait } & 1 & $-1.7+1.14($ log age $)$ & 0.14 & $91 \%$ \\
\hline & 2 & $18.3-3.76($ log age $)$ & 2.2 & $33 \%$ \\
\hline
\end{tabular}

Table 7. Results of testing homogeneity of rates of change in cancer counts with respect to age. P-values above 0.05 indicate that the hypothesis of homogeneity is supported by the data.

\begin{tabular}{cccc}
\hline Cancer & Phase & Chi-square & p-value \\
\hline \multirow{2}{*}{ BC } & 1 & 8.18 & 0.394 \\
& 2 & 2.97 & 0.704 \\
\multirow{2}{*}{ OC } & 1 & 5.06 & 0.409 \\
& 2 & 0.39 & 0.995 \\
\hline
\end{tabular}

since 1990. The trend is a particular threat to developing nations with health systems that are ill-equipped to deal with complex and expensive cancer treatments. The annual update provided by the national cancer registries on the regional burden of cancer will provide all stakeholders with timely estimates to guide policy efforts in cancer prevention, screening, treatment, and palliation. Together with the registry of cancer incidence there is a need for an integrated system of surveillance of the associated risk factors. Therefore one can monitor the correlation between the trend of increase/decrease in the risk factors and the trend of increase/decrease in the cancer incidence. Therefore a systematic investigation of cancer pattern and trends in the AGS over the next decades become feasible, and such information will help the council of health ministers for the design, implementation, the evaluation, and intervention in the AGS.

\section{Acknowledgements}

The authors are thankful for the constructive comments made by anonymous reviewer.

\section{Conflict of Interest}

The authors declare that they have no conflict of interest.

\section{References}

[1] World Health Organization (2008) The Global Burden of Disease: 2004 Update. World Health Organization, Geneva.

[2] Antoniou, A., Pharoah, P.D., Narod, S., et al. (2003) Average Risks of Breast and Ovarian Cancer Associated with BRCA1 or BRCA2 Mutations Detected in Case Series Unselected for Family History: A Combined Analysis of 22 Studies. American Journal of Human Genetics, 72, 1117-1130. http://dx.doi.org/10.1086/375033 
[3] Howlader, N., Noone, A.M., Krapcho, M., et al. (2013) SEER Cancer Statistics Review, 1975-2011. National Cancer Institute, Bethesda, MD.

[4] Foulkes, W.D. (2014) BRCA1 and BRCA2-Update and Implications on the Genetics of Breast Cancer Clinical Perspective. Clinical Genetics, 85, 1-4. http://dx.doi.org/10.1111/cge.12291

[5] Chen, S. and Parmigiani, G. (2007) Meta-Analysis of BRCA1 and BRCA2 Penetrance. Journal of Clinical Oncology; 25, 1329-1333. http://dx.doi.org/10.1200/JCO.2006.09.1066

[6] Castilla, L.H., Couch, F.J., Erdos, M.R., Hoskins, K.F., Calzone, K., Garber, J.E., et al. (1994) Mutations in the BRCAl Gene in Families with Early-Onset Breast and Ovarian Cancer. Nature Genetics, 8, 387-389. http://dx.doi.org/10.1038/ng1294-387

[7] Ballard-Barbash, R., Hunsberger, S. and Alciati, M.H. (2009) Physical Activity, Weight Control, and Breast Cancer Risk and Survival: Clinical Trial and Rationale Considerations. Journal of the National Cancer Institute, 101, 630-643. http://dx.doi.org/10.1093/jnci/djp068

[8] Wang, Y.C., McPherson, K., Marsh, T., Gortmaker, S.L. and Brown, M. (2011) Health and Economic Burden of the Projected Obesity Trends in the USA and UK. Lancet, 378, 815-825. http://dx.doi.org/10.1016/S0140-6736(11)60814-3

[9] Gakidou, E., et al. (2014) Global, Regional and National Prevalence of Overweight and Obesity in Children and Adults: 1980-2013: A Systematic Analysis. Lancet, 384, 766-781.

[10] Shaw, J.E., Sicree, R.A. and Zimmet, P.Z. (2010) Global Estimates of the Prevalence of Diabetes for 2010 and 2030. Diabetes Research and Clinical Practice, 87, 4-14. http://dx.doi.org/10.1016/j.diabres.2009.10.007

[11] Fitzmaurice, C., Dicker, D., Pain, A., Hamavid, H., Moradi-Lakeh, M., MacIntyre, M.F., Allen, C., Hansen, G., Woodbrook, R., Wolfe, C., Hamadeh, R.R., Moore, A., Werdecker, A., Gessner, B.D., Te Ao, B., McMahon, B., Karimkhani, C., Yu, C., Cooke, G.S., Schwebel, D.C., Carpenter, D.O., Pereira, D.M., Nash, D., Kazi, D.S., De Leo, D., Plass, D., Ukwaja, K.N., Thurston, G.D., Jin, K.Y., Simard, E.P., Mills, E., Park, E., Catala-Lopez, F., de Veber, G., Gotay, C., Khan, G., Hosgood, H.D., Santos, I.S., Leasher, J.L., Singh, J., Leigh, J., Jonas, J., Sanabria, J., Beardsley, J., Jacobsen, K.H., Takahashi, K., Franklin, R.C., Ronfani, L., Montico, M., Naldi, L., Tonelli, M., Geleijnse, J., Petzold, M., Shrime, M.G., Younis, M., Yonemoto, N., Breitborde, N., Yip, P., Pourmalek, F., Lotufo, P.A., Esteghamati, A., Hankey, G.J., Ali, R., Lunevicius, R., Malekzadeh, R., Dellavalle, R., Weintraub, R., Lucas, R., Hay, R., Rojas-Rueda, D., Westerman, R., Sepanlou, S.G., Nolte, S., Patten, S., Weichenthal, S., Abera, S.F., Fereshtehnejad, S.M., Shiue, I., Driscoll, T., Vasankari, T., Alsharif, U., Rahimi-Movaghar, V., Vlassov, V.V., Marcenes, W.S., Mekonnen, W., Melaku, Y.A., Yano, Y., Artaman, A., Campos, I., MacLachlan, J., Mueller, U., Kim, D., Trillini, M., Eshrati, B., Williams, H.C., Shibuya, K., Dandona, R., Murthy, K., Cowie, B., Amare, A.T., Antonio, C.A., Castaneda-Orjuela, C., van Gool, C.H., Violante, F., Oh, I.H., Deribe, K., Soreide, K., Knibbs, L., Kereselidze, M., Green, M., Cardenas, R., Roy, N., Tillman, T., Li, Y., Krueger, H., Monasta, L., Dey, S., Sheikhbahaei, S., Hafezi-Nejad, N., Kumar, G.A., Sreeramareddy, C.T., Dandona, L., Wang, H., Vollset, S.E., Mokdad, A., Salomon, J.A., Lozano, R., Vos, T., Forouzanfar, M., Lopez, A., Murray, C. and Naghavi, M. (2016) Global Burden of Disease Cancer Collaboration. The Global Burden of Cancer 2013. JAMA Oncology, 1, 505-527.

[12] National Center for Health Statistics CDCP (2006) US Mortality Public Use Data Tapes, 1969-2003.

[13] Lipscomb, J., Donaldson, M.S. and Hiatt, R.A. (2004) Cancer Outcomes Research and the Arenas of Application. Journal of The National Cancer Institute Monographs, 33, 1-7. http://dx.doi.org/10.1093/jncimonographs/lgh038

[14] Costanzo, E.S., Lutgendorf, S.K., Rothrock, N.E. and Anderson, B. (2006) Coping and Quality of Life among Women Extensively Treated for Gynecologic Cancer. Psycho-oncology, 15, 132-142. http://dx.doi.org/10.1002/pon.930

[15] Spiegel, D. (1996) Cancer and Depression. British Journal of Psychiatry, 168, 109-116.

[16] Lopez, A.D., Mathers, C.D., Ezzati, M., Jamison, D.T. and Murray, C.J.L. (2006) Global Burden of Disease and Risk Factors. Oxford University Press, New York. http://dx.doi.org/10.1596/978-0-8213-6262-4

[17] Murray, C.J., Vos, T., Lozano, R., et al. (2013) Disability-Adjusted Life Years (DALYs) for 291 Diseases and Injuries in 21 Regions, 1990-2010: A Systematic Analysis for the Global Burden of Disease Study 2010. Lancet, 380, 2197 2223. http://dx.doi.org/10.1016/S0140-6736(12)61689-4

[18] Center for Cancer Control and Prevention (2010) Cancer Incidence among Nationals of the GCC States, $1998-2009$. Annual Report.

[19] Lilienfeld, A. and Johnson, E. (1955) The Age Distribution in Female Breast and Genital Cancers. Cancer, 8, 875-882. http://dx.doi.org/10.1002/1097-0142(1955)8:5<875::AID-CNCR2820080504>3.0.CO;2-Z

[20] Doll, R. (1971) The Age Distribution of Cancer: Implications for Models of Carcinogenesis. Journal of the Royal Statistical Society, 134, 133-166. http://dx.doi.org/10.2307/2343871 


\section{Submit or recommend next manuscript to SCIRP and we will provide best service for you:}

Accepting pre-submission inquiries through Email, Facebook, LinkedIn, Twitter, etc.

A wide selection of journals (inclusive of 9 subjects, more than 200 journals)

Providing 24-hour high-quality service

User-friendly online submission system

Fair and swift peer-review system

Efficient typesetting and proofreading procedure

Display of the result of downloads and visits, as well as the number of cited articles

Maximum dissemination of your research work

Submit your manuscript at: http://papersubmission.scirp.org/ 